\title{
THE EVERYWHERE BUS
}

\section{It's the latest in travel technology.}

\section{BY JONATHAN L. HOWARD}

$\mathrm{T}$ hank you! Thank you, one and all. Today is an auspicious day, a day born from the darkest weeks and months our species has ever experienced, a time when we nightly wondered whether humanity might see even one more dawn. But we prevailed. Yog-Sothoth is no more. The very quality that made him such a capable foe - his omnipresence throughout all space and time - at last proving his downfall when we realized that, as he was everywhere at once, that meant he was at the top of every flight of stairs in creation. Humanity pushed together, Yog-Sothoth took all conceivable tumbles, and broke his neck everywhere, the coup de grâce being delivered by a small girl in Hunan province, China, who kicked his arse off a cliff on Tianmen Mountain. Well done you, little girl.

This, of course, left us with a new problem - what to do with a corpse that is coterminous with all space-time. After discussions, we decided upon a radical course of action. We have hollowed Yog-Sothoth out, bolted on some wheels, and converted his carcass into ... the Everywhere Bus!

(What did we do with his innards? Oh ... this and that.)

This represents a new golden age for humanity. Being everywhere, one need only board the Bus to already be at your destination, anywhere in the world. Let me explain to you how one goes about it. First one needs an Everywhere ticket, available from newsagents, libraries and ice-cream vans. One flat fee to pay, which, you will notice, is very cheap. Well, the Everywhere Bus needs no maintenance, and it is as little trouble to go half a mile to the High Street as it is to go to the moons of Saturn.

Incidentally, don't go to the moons of Saturn without seeking expert advice beforehand.

The procedure is simple. First, flag down the Bus. You don't have to be at a bus stop for this, or even outside. Just stand, hold out the ticket thus, and the Bus will stop for you.

Smartly mount the step and present your ticket to the Driver. There is only one Driver. Because navigating all of creation in an instant while still remembering where the low bridges are is a role unsuitable for the frail human mind, an army of conceptual mathematicians laboured day and night to create ... this.

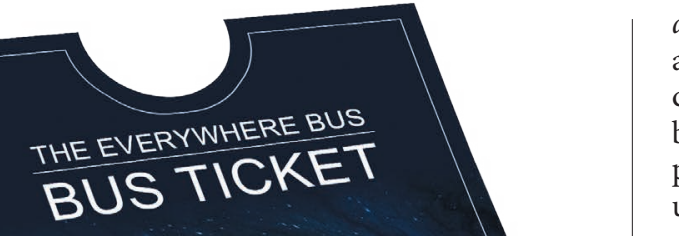

always be the first one. At this point, simply alight from the Bus, and you will be at your destination, your ticket will return to its base state of architectural computation and pass from you in the way that mathematics usually does.

Now, some important points. You will have noticed I told you that your stop is invariably the first one. Some of you are probably asking yourself questions like, What if I go along two stops? Or If the Bus is coterminous with all space-time, you may wonder, what if I travel in time as well as space? What, you may say, if I leave an empty crisp packet aboard the Bus?

To address these points in order, you will threaten creation, you will threaten causality, and you're a litterbug.

These are all offences under the Bus Company by-laws.

To deal with this, after they'd finished creating Dave the Driver, the conceptual mathematicians created Inspector Blake. Inspector Blake has an encyclopaedic knowledge of the by-laws as they are quite literally his raison d'etre, and are encoded into the very fabric of his being. Inspector Blake has an underdeveloped sense of humour and an irritating laugh. If you are found in breach of the by-laws, you may be subjected to an on-the-spot fine or - for serious infractions - you will be put off the Bus. This is to be avoided as this will place you everywhere simultaneously, and - as an average person being forced to exist universally coterminous with all space-time and lacking the panache of a Yog-Sothoth - you will be spread thinner than boarding-house jam across all 23 dimensions.

It's not worth it. Obey the by-laws.

Well, I think that's all that needs to be said for the moment. Buy a pack of tickets from your local newsagent, library or ice-cream van today, and embrace the Universe tomorrow! Just don't look out of the windows while travelling, do not antagonize Inspector Blake, and I'd avoid Penge high street for the time being.

Good luck! Happy travelling! Don't go insane! the corpse of a non-Euclidean alien god; why would I choose this moment to start talking figuratively?

To continue. Pay $\rightarrow$ NATURE.COM

Follow Futures: @NatureFutures

f go.nature.com/mtoodm attention so you don't miss your stop. It will be the first one. It will

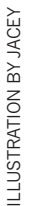
(a) 